\title{
Stimulation of $\boldsymbol{\gamma}$-Aminobutyric Acid Synthesis Activity in Brown Rice by a Chitosan/Glutamic Acid Germination Solution and Calcium/Calmodulin
}

\author{
Suk-Heung Oh* \\ Department of Biotechnology, Woosuk University, Jeonju 565-701, Korea
}

Received 24 December 2002, Accepted 10 February 2003

Changes in the concentrations of $\boldsymbol{\gamma}$-aminobutyric acid (GABA), soluble calcium ions, glutamic acid, and the activity of glutamate decarboxylase (GAD) were investigated in non-germinated vs. germinated brown rice. Brown rice was germinated for $72 \mathrm{~h}$ by applying each of the following solutions: (1) distilled water, (2) $5 \mathrm{mM}$ lactic acid, (3) $50 \mathrm{ppm}$ chitosan in $5 \mathrm{mM}$ lactic acid, (4) $5 \mathrm{mM}$ glutamic acid, and (5) $50 \mathrm{ppm}$ chitosan in $5 \mathrm{mM}$ glutamic acid. GABA concentrations were enhanced in all of the germinated brown rice when compared to the nongerminated brown rice. The GABA concentration was highest in the chitosan/glutamic acid that germinated brown rice at $2,011 \mathrm{nmol} / \mathrm{g}$ fresh weight, which was 13 times higher than the GABA concentration in the nongerminated brown rice at $154 \mathrm{nmol} / \mathrm{g}$ fresh weight. The concentrations of glutamic acid were significantly decreased in all of the germinated rice, regardless of the germination solution. Soluble calcium and GAD were higher in the germinated brown rice with the chitosan/ glutamic acid solution when compared to the rice that was germinated in the other solutions. GAD that was partially purified from germinated brown rice was stimulated about 3.6-fold by the addition of calmodulin in the presence of calcium. These data show that the germination of brown rice in a chitosan/glutamic acid solution can significantly increase GABA synthesis activity and the concentration of GABA.

Keywords: Brown rice, Chitosan, GABA, Germination, Glutamic acid

\section{Introduction}

$\gamma$-Aminobutyric acid (GABA) is a nonprotein amino acid that is primarily produced from the $\alpha$-decarboxylation of $\mathrm{L}$ glutamic acid (Glu) that is catalyzed by the enzyme glutamate decarboxylase (GAD) (Satyanarayan and Nair, 1990; Choi et al., 1998, Park et al., 1999). GABA functions in animals as a major inhibitory neurotransmitter (Erlander and Tobin, 1991; Mody et al., 1994).

For at least a half century the presence of GABA in plants has been known (refs. in Satyanarayan and Nair, 1990). However, the GABA role in plants is still unclear. GABA may have a role in $\mathrm{pH}$ regulation (Bown and Shelp 1997), N storage (Selman and Cooper, 1978), plant development (Baum et al., 1996), and in the plant's defense against phytophagous insects (Ramputh and Bown, 1996).

Recently, there has been an increased interest in the utilization of GABA as a bioactive plant component. Several lines of evidence suggest that plant extracts containing high levels of GABA are effective in blood pressure regulation (Omori et al., 1987; Nakagawa and Onota, 1996) and in the recovery of alcohol-related symptoms (Nakagawa and Onota, 1996; Oh and Cha, 2001). Reportedly, GABA levels in plants are enhanced during high stress conditions, such as mechanical stimulation, hypoxia, cytosolic acidification, water, darkness, and drought (Serraj et al., 1998; Snedden and Fromm 1998; Shelp et al., 1999). Interestingly, many of these same stresses that induce GABA production in plants also cause transient increases in cytosolic $\mathrm{Ca}^{2+}$ concentrations (Knight et al. 1991). Transient elevations in cytosolic $\mathrm{Ca}^{2+}$ are metabolic signals that are transmitted through $\mathrm{Ca}^{2+}$-modulated proteins, such as calmodulin. $\mathrm{Ca}^{2+}$-stimulated GAD activity was first observed by screening a cDNA expression library from petunia with ${ }^{35} \mathrm{~S}$-labeled calmodulin (Baum et al. 1993). A cDNA coding for a $\mathrm{Ca}^{2+}$-dependent calmodulin-binding protein was isolated and the recombinant protein showed GAD activity (Baum et al. 1993). Ling et al. (1994) demonstrated that plant $\mathrm{GAD}$ is stimulated by $\mathrm{Ca}^{2+}$ calmodulins; Snedden et al. (1995) showed that soybean
*To whom correspondence should be addressed

Tel: 82-63-290-1433; Fax: 82-63-291-9312

E-mail: shoh@core.woosuk.ac.kr 
GAD is a $\mathrm{Ca}^{2+} /$ calmodulin-dependent enzyme.

In this study, the effects of calcium and calmodulin on the activation of GAD were evaluated in partially purified GAD from germinated brown rice. We were able to demonstrate the $\mathrm{Ca}^{2+} /$ calmodulin-dependent activation of rice GAD. Furthermore, we were able to show that the germination of rice with chitosan that was dissolved in a glutamic acid solution significantly increased the concentrations of GABA and GABA synthesis activity.

\section{Materials and Methods}

Materials Flasks with side arms for the GAD assays were purchased from Kontes (Vineland, USA). DEAE-cellulose, bisTris, dithiothreitol (DTT), ethylenediamine tetra-acetic acid (EDTA), ethyleneglycol-bis- $\beta$-aminoethyl ether, N, N, N', N'tetraacetic acid (EGTA), $\gamma$-aminobutyric acid (GABA), pyridoxal5'-phosphate (PLP), phenylmethyl-sulfonyl fluoride (PMSF), and polyvinyl-polypyrrolidone (PVPP) were obtained from the Sigma Chemical Co. (St. Louis, USA). L- $\left[1-{ }^{14} \mathrm{C}\right]$ glutamic acid $(55.0 \mathrm{mCi} /$ mmol) was purchased from Amersham (Little Chalfont, England). The calcium standard solution for the ion chromatography was obtained from Dionex (Sunnyvale, USA). Chitosan was supplied by El-Chitosan Korea Co., Ltd. in Jeonju, Korea. Brown rice was obtained from a Jeonju market place in Korea. All of the other reagents were purchased from commercial sources and were of the highest available grade.

Germination of brown rice Brown rice was surface-washed 3 times with double-distilled water. The brown rice $(50 \mathrm{~g})$ was soaked in the following solutions at $25-26^{\circ} \mathrm{C}$ in the dark for $72 \mathrm{~h}$ : (1) distilled water (W), (2) $5 \mathrm{mM}$ lactic acid (L), (3) 50 ppm chitosan in $5 \mathrm{mM}$ lactic acid (CL), (4) $5 \mathrm{mM}$ glutamic acid (G), and (5) $50 \mathrm{ppm}$ chitosan in $5 \mathrm{mM}$ glutamic acid (CG). The solutions were changed every $12 \mathrm{~h}$ with freshly prepared solutions. The germinated brown rice was air dried, frozen in liquid nitrogen, ground with a mortar and pestle, and extracted as described below.

Extraction and analysis of GABA and glutamic acid GABA and free amino acids were extracted using the procedures of Baum et al. (1996) with modifications as described (Oh and Choi, 2001). The ground samples ( $200 \mathrm{mg}$ ) were thawed in $800 \mu$ l of a mixture of methanol:chloroform:water $12: 5: 3(\mathrm{v} / \mathrm{v} / \mathrm{v})$. The mixture was vortexed and then centrifuged at $13,000 \times g$ at $4^{\circ} \mathrm{C}$ for $15 \mathrm{~min}$. The supernatant was collected, then $200 \mu \mathrm{l}$ chloroform and $400 \mu \mathrm{l}$ water were added to the pellet. The resulting mixture was vortexed and centrifuged for $15 \mathrm{~min}$ at $13,000 \times \mathrm{g}$. The supernatant was collected and combined with the first supernatant and recentrifuged to collect the upper phase. The collected samples were dried in a freeze-dryer and redissolved in water. The resulting samples contained GABA, glutamic acid, and other amino acids. Each sample was passed through a $0.45 \mu \mathrm{m}$ filter and analyzed by an amino acid analysis system (Waters, USA) after 6-aminoquioly-N-hydroxysuccinimidyl carbonate (AQC) derivatization.

Analysis of GAD activity GAD was assayed using the procedures described by $\mathrm{Oh}$ and Choi (2001). The groundgerminated rice samples $(\sim 200 \mathrm{mg})$ were thawed in a $50 \mathrm{mM}$ bisTris-HCl (pH 7.0) buffer containing 2 mM EDTA, 1 mM DTT, 0.1 $\mathrm{mM}$ PLP, $1 \mathrm{mM}$ PMSF, $2 \%(\mathrm{w} / \mathrm{v})$ PVPP, and 10\% (v/v) glycerol. The homogenate was centrifuged at $13,000 \times g$ for $15 \mathrm{~min}$ at $4^{\circ} \mathrm{C}$ and the supernatant collected. The total protein concentration was determined according to the method of Bradford (1976) using a Coomassie blue reagent (Bio-Rad) with $\gamma$-globulin as the standard protein. The GAD assay was performed using the radiometric method that is based on $\mathrm{L}-\left[1-{ }^{14} \mathrm{C}\right] \mathrm{Glu}$-dependent ${ }^{14} \mathrm{CO}_{2}$ production (Snedden et al. 1995) with modifications. The samples were incubated in a shaking water bath at $30^{\circ} \mathrm{C}$ for $30 \mathrm{~min}$ in $25 \mathrm{ml}$ sealed flasks with side arms containing a $\mathrm{CO}_{2}$ trap of $0.4 \mathrm{ml}$ of $0.1 \mathrm{~N} \mathrm{NaOH}$ and $2 \mathrm{ml}$ of the reaction mixture. The reaction mixture consisted of a $20-100 \mu \mathrm{l}$ protein sample, $100 \mathrm{mM}$ bis-Tris- $\mathrm{HCl}$ buffer ( $\mathrm{pH} 7.0$ ), $1 \mathrm{mM}$ DTT, $2.5 \mathrm{mM} \mathrm{CaCl}, 200 \mathrm{nM}$ calmodulin, $0.5 \mathrm{mM}$ PLP, and $10 \%(\mathrm{v} / \mathrm{v})$ glycerol with $2.5 \mathrm{mM}$ L-glutamate $(0.1 \mu \mathrm{Ci} /$ reaction, Amersham). All of the reactions were initiated by injecting these protein extracts with a micro-syringe through a rubber stopper on the side arm into the reaction medium. The reactions were incubated for $25 \mathrm{~min}$ and then terminated by an injection of $0.2 \mathrm{ml}$ of $9 \mathrm{~N} \mathrm{H}_{2} \mathrm{SO}_{4}$. The reaction flasks were left at $4^{\circ} \mathrm{C}$ overnight to ensure the complete evolution of $\mathrm{CO}_{2}$ and absorption by the sodium hydroxide trap before the ${ }^{14} \mathrm{C}$ content of the $\mathrm{CO}_{2}$ trap was determined using a liquid scintillation counter (Beckman, USA).

Partial purification of GAD from germinated brown rice GAD from germinated brown rice was partially purified by a combination of ammonium sulfate precipitation and anionexchange chromatography, as previously described (Ling et al., 1994; Oh and Yun, 1999), with slight modifications. Brown rice that was germinated $72 \mathrm{~h}$ in a CG solution was harvested and immediately frozen in liquid nitrogen. The samples were ground to a fine powder with a mortar and pestle and transferred to $50 \mathrm{mM}$ bis-Tris-HCl (pH 7.0), $1 \mathrm{mM}$ EDTA, $1 \mathrm{mM}$ DTT, $0.1 \mathrm{mM}$ PLP, $1 \mathrm{mM}$ PMSF, 2\% (w/v) PVPP, and 10\% (v/v) glycerol. The homogenate was centrifuged at $23,000 \times g$ for $20 \mathrm{~min}$ and the supernatant was used to prepare a 20 to $60 \%(\mathrm{w} / \mathrm{v})$ ammonium sulfate pellet, which was solubilized in an extraction buffer. The sample was then dialyzed overnight at $4^{\circ} \mathrm{C}$ against a $50 \mathrm{mM}$ bisTris-HCl (pH 7.0) buffer containing $1 \mathrm{mM}$ EDTA, $1 \mathrm{mM}$ DTT, $1 \mathrm{mM}$ PMSF, and $10 \%(\mathrm{v} / \mathrm{v})$ glycerol. The sample was applied to a $2.5 \times 10 \mathrm{~cm}$ column of DEAE-cellulose that was pre-equilibrated with the dialysis buffer and washed with the same buffer. After washing, the column was eluted with a linear $\mathrm{NaCl}$ gradient $(0 \sim 1.0$ $\mathrm{M})$ in an equilibration buffer. The enzyme peak was pooled and concentrated by ultrafiltration on an Amicon YM-10 membrane.

Calcium extraction and concentration Soluble calcium was extracted and the concentration was measured by the procedures of Oh and Choi (2001). The ground samples ( $200 \mathrm{mg}$ ) were thawed in $800 \mu 1$ of double-deionized water and vortexed. The homogenate was microcentrifuged at $12,000 \mathrm{rpm}$ for $15 \mathrm{~min}$ at $4^{\circ} \mathrm{C}$ and the supernatant collected. The resulting samples containing the calcium ions were passed through $0.45 \mu \mathrm{m}$ filters and analyzed by a DX500 ion chromatography system with an IonPac CS12A cation column (Dionex, USA). 


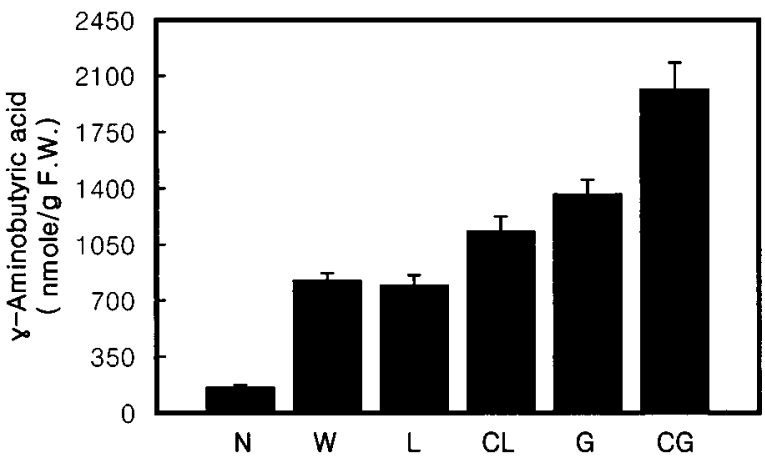

Fig. 1. Increased concentrations of GABA in chitosan/glutamic acid germinated brown rice. Brown rice was germinated in distilled water (W), lactic acid (L), chitosan/lactic acid (CL), in glutamic acid (G), and chitosan/glutamic acid (CG) solutions. GABA was extracted from the non-germinated and germinated brown rice and analyzed as described in Materials and Methods. Each bar represents the average of three determinations with error bars showing the standard error of the mean. $\mathrm{N}$, nongerminated brown rice.

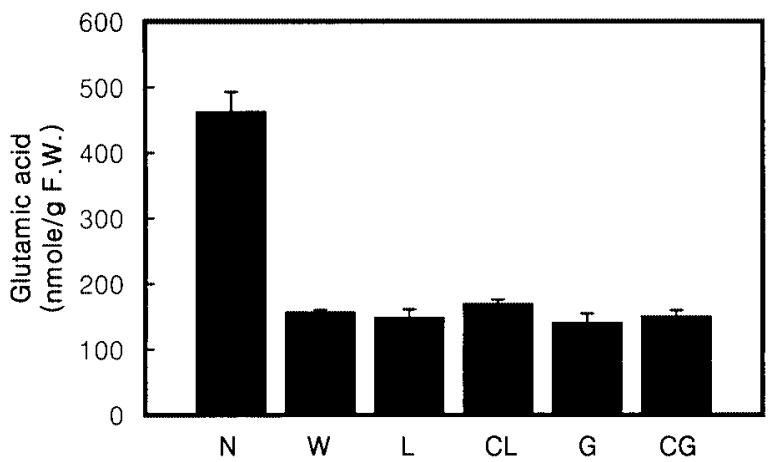

Fig. 2. Decreased concentrations of glutamic acid in germinated brown rice. Brown rice was obtained and analyzed as described in the legend of Fig. 1. Each bar represents the average of three determinations with error bars showing the standard error of the mean. $\mathrm{N}$, non-germinated brown rice; $\mathrm{W}$, brown rice germinated in water; $\mathrm{L}$, brown rice germinated in lactic acid; $\mathrm{CL}$, brown rice germinated in chitosan/lactic acid; G, brown rice germinated in glutamic acid; CG, brown rice germinated in chitosan/glutamic acid.

\section{Results}

Increases in the concentrations of GABA and decreases in Glu in germinated brown rice GABA and free amino acids, including glutamic acid (Glu), were extracted from the non-germinated and germinated brown rice, and analyzed by an amino acid analyzer after AQC derivatization. The GABA concentration changes in the germinated brown rice are shown in Fig. 1. GABA was enhanced in all of the germinated brown rice, but the highest GABA increase was found in the brown rice that was germinated with the chitosan/glutamic acid (CG) solution. The GABA concentrations in the $\mathrm{CG}$ rice was 13 times, 2.5 times, 2 times, and 1.5 times higher than in the non-

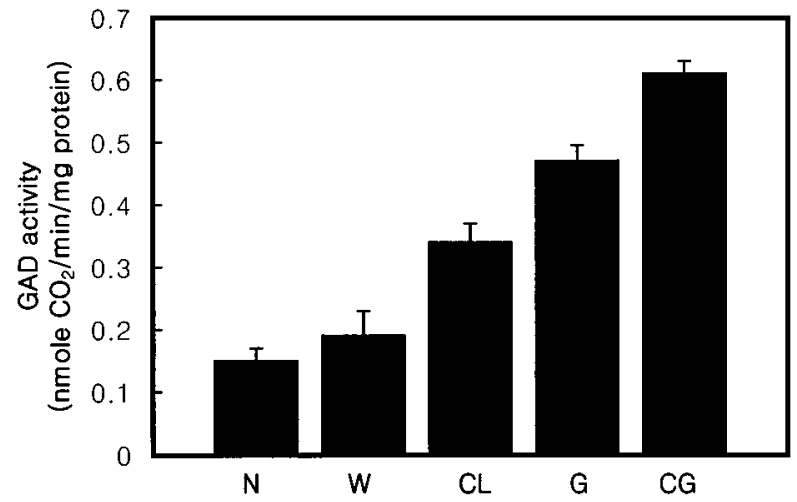

Fig. 3. Changes in GAD activity by the germination of brown rice. GAD was extracted from the brown rice, and the activity was assayed as described in Materials and Methods. Values are the averages of three determinations with error bars showing the standard errors of the means. N, non-germinated brown rice; W, brown rice germinated in water; CL, brown rice germinated in chitosan/lactic acid; G, brown rice germinated in glutamic acid; $\mathrm{CG}$, brown rice germinated in chitosan/glutamic acid.

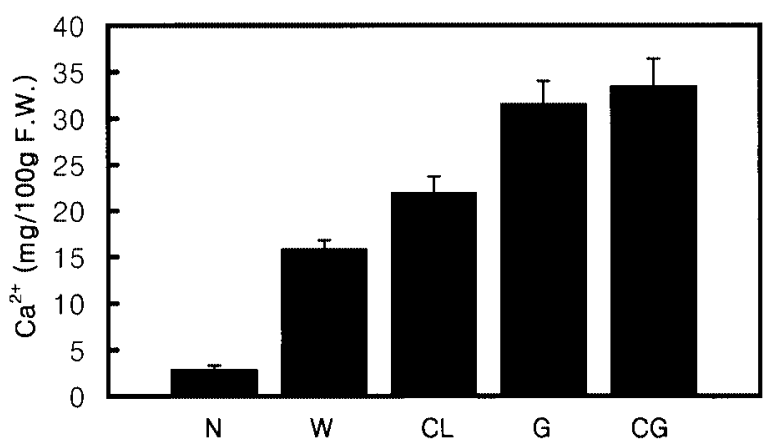

Fig. 4. Changes in the concentrations of $\mathrm{Ca}^{2+}$ by the germination of brown rice. $\mathrm{Ca}^{2+}$ was extracted from the brown rice and analyzed by ion chromatography as described in Materials and Methods. Each bar represents the average of three determinations with error bars showing the standard error of the mean. N, nongerminated brown rice; $\mathrm{W}$, brown rice germinated in water; $\mathrm{CL}$, brown rice germinated in chitosan/lactic acid; $\mathrm{G}$, brown rice germinated in glutamic acid; $\mathrm{CG}$, brown rice germinated in chitosan/glutamic acid.

germinated $(\mathrm{N})$, water germinated (W) or lactic acid germinated (L), chitosan/lactic acid (CL) germinated, and glutamic acid $(\mathrm{G})$ germinated brown rice, respectively (Fig. 1). On the other hand, the highest Glu levels were found in the non-germinated brown rice (Fig. 2). The Glu levels declined greatly in all of the germinated brown rice samples, regardless of the soaking solutions.

Increases in the levels of GAD and soluble calcium in germinating brown rice The specific GAD activity in the sample extracts was determined using a radiometric GAD assay (Snedden et al., 1995). GAD activity was very low in the $\mathrm{N}$ brown rice, but significantly higher in the germinated 
rice (Fig. 3). The highest GAD level was found in the $\mathrm{CG}$ germinated brown rice, which was about 4-fold higher than the activity that was determined in the $\mathrm{N}$ rice, and about 3-fold higher than in the $\mathrm{W}$ rice (Fig. 3). The soluble calcium concentrations were also increased in the germinated brown rice (Fig. 4), when compared with the $\mathrm{N}$ brown rice; the highest concentrations were in the CG brown rice (Fig. 4).

Stimulation of rice GAD activity by calcium and calmodulin To determine whether rice GAD is activated by calmodulin and whether it is $\mathrm{Ca}^{2+}$-dependent, the GAD activity was measured in the presence or absence of $\mathrm{Ca}^{2+}$ and calmodulin. The addition of both $\mathrm{Ca}^{2+}$ and calmodulin increased the GAD activity, but combining the two had more of an additive effect (Table 1).

\section{Discussion}

The effects of germination and germination conditions on the concentrations of GABA, Glu, GAD and soluble calcium ions were evaluated in brown rice. Germination resulted in significant increases in the GABA concentrations that could be further increased by additions to the soaking solution that was used for the germination; the highest GABA concentrations were obtained by germination with the chitosan/glutamic acid (CG) solution. The CG-germinated brown rice also appeared to have higher GAD levels when compared to the non-germinated and water germinated brown rice. The concentration of calcium ions was also higher in the CG-germinated brown rice than in the non-germinated brown rice. In contrast, the highest Glu concentrations were found in the non-germinated brown rice; the Glu levels were very low in the germinated brown rice. Overall, the data clearly show that the concentrations of GABA, GAD, and soluble calcium are significantly increased by germination of the brown rice, with the greatest increase in the CG-germinated brown rice, while Glu is highest in the non-germinated brown rice.

Previously, we demonstrated that the germination of brown rice in chitosan or glutamic acid solutions increased the GABA concentrations when compared to the non-germinated or water-germinated brown rice (Oh and Choi, 2000; Oh et al., 2002); however, this study demonstrated that combining the glutamic acid and chitosan resulted in greater increases than when using either alone (Fig. 1). Several organic acids (including: lactic acid, acetic acid, glutamic acid, tartaric acid, citric acid, etc.) can be used to increase the solubility of chitosan (Jung et al., 1999). Our results demonstrate that glutamic acid, especially when combined with chitosan, increases the GABA accumulation more than the other organic acids or than lactic acid with chitosan (Fig. 1). These results suggest that chitosan and glutamic acid have a synergistic effect on the increase in GABA synthesis (see below for further discussion).

Interestingly, the Glu concentrations were unchanged by the germination of brown rice in either the CG or G solution, but the germination significantly increased the GABA concentrations (Figs. 1 and 2). Glu that influxed from the $\mathrm{CG}$ solution, as well as the endogenous Glu, could be used as the key substrate of GAD during the germination of brown rice. In this regard, it is interesting to note that transgenic tobacco plants that expressed the petunia GAD gene had a marked increase in GABA and decrease in Glu concentrations (Baum et al., 1996). The GABA-shunt pathway may provide carbon skeletons for oxidation in the tricarboxylic acid cycle, an important step during germination (Vandewalle and Olsson, 1983). GABA was also postulated to have a role in nitrogen storage and metabolism in plants (Selman and Cooper, 1978). GABA in nutrient solutions can function as a sole nitrogen source for plant growth (Shelp et al., 1995). Other possible GABA functions in plants may include a role in the plant's defense against phytophagous insects (Ramputh and Bown 1996) and in disease resistance (Ling et al., 1994). Aminobutyric acid isomers $(\alpha, \beta$, and $\gamma)$ induce pathogenesisrelated protein synthesis in plants, such as $\beta-1,3$ glucanases, and chitinases (Cohen et al., 1994). Future studies, including an analysis of pathogenesis-related enzymes, may provide insight into the significance of GABA production during the germination of brown rice.

It has been reported that chitosan can function as a plant cell elicitor (Pearce and Ride, 1982; Notsu et al., 1994). Therefore, it is possible that chitosan, like other stimuli, activates the mobilization and redistribution of calcium ions in plant cells (Bach et al., 1993). There is increasing evidence that changes in calcium concentrations in response to environmental stimuli serves as a major second messenger and evokes a number of cellular responses in plants (Hepler and Wayne, 1985; Knight et al., 1991). Our results provide evidence that the external environment (i.e. the soaking solution) is important to the induction of the synthesis of calcium-dependent enzymes, such as GAD, and to the bioavailability of calcium in germinating seeds (Figs. 3 and 4).

The increased activation of rice GAD by $\mathrm{Ca}^{2+} /$ calmodulin (355\%) was higher than the reported increases in the activation of petunia GAD (276\%) (Arazi et al., 1995) and Vicia fava root GAD (212\%) (Ling et al., 1994). The stimulation of GAD, even in the absence of added calmodulin (Table 1, control and $+\mathrm{Ca}^{2+}$ ), may be interpreted as evidence for bound calmodulin. Bound calmodulin in final protein preparations results in the high background activity of the plant $\mathrm{Ca}^{2+} /$ calmodulin-dependent enzymes (Collinge and Trewavas, 1989; Rasi-Caldogno et al., 1993). A small increase in GAD activity with calmodulin in the absence of $\mathrm{Ca}^{2+}$ may be explained by calmodulin/GAD interactions in the absence of $\mathrm{Ca}^{2+}$ (Arazi et al., 1995). In order to exclude the possibility that bound calmodulin may not be removed during the partial purification of GAD, it would be helpful to an E. coli expression system. Previously, we showed that GAD, which is purified from $E$. coli that carries a plasmid containing the tobacco GAD gene, exhibits about a 60-fold increase in $\mathrm{Ca}^{2+} /$ 
Table 1. Calcium/calmodulin dependent activation of partially purified rice $\mathrm{GAD}^{\mathrm{a}}$

\begin{tabular}{ccc}
\hline & \multicolumn{2}{c}{ Activity } \\
\cline { 2 - 3 } Treatment & $\begin{array}{c}\mathrm{nmol} \mathrm{CO}_{2} / \mathrm{min} / \mathrm{mg} \\
\text { protein }\end{array}$ & $\%$ of control \\
\hline Control $\left(-\mathrm{Ca}^{2+},-\mathrm{CaM}\right)$ & $15.6(0.7)^{\mathrm{b}}$ & 100 \\
$+\mathrm{Ca}^{2+}$ & $23.4(0.9)$ & 150 \\
$+\mathrm{CaM}^{2+}$ & $21.8(0.8)$ & 140 \\
$+\mathrm{Ca}^{2+} / \mathrm{CaM}$ & $55.4(1.1)$ & 355 \\
\hline
\end{tabular}

${ }^{\mathrm{a}} \mathrm{GAD}$ was partially purified from germinated brown rice extract through a combination of ammonium sulfate precipitation (20 60\% saturation) and DEAE-cellulose column chromatography. GAD assay was performed as described in Materials and Methods without the addition of $\mathrm{Ca}^{2+}$ and calmodulin $(\mathrm{CaM})$ (control), and with the addition of $2.5 \mathrm{mM} \mathrm{CaCl}_{2}\left(+\mathrm{Ca}^{2+}\right), 200$ $\mathrm{nM}$ VU-1 calmodulin $(+\mathrm{CaM})$, and $2.5 \mathrm{mM} \mathrm{CaCl}_{2}$ and $200 \mathrm{nM}$ VU-1 calmodulin $\left(+\mathrm{Ca}^{2+} / \mathrm{CaM}\right)$.

${ }^{\text {b}}$ Values represent the means of three independent determinations with standard errors shown in parenthesis.

calmodulin-dependent activation. The activity was not stimulated by the addition of $\mathrm{Ca}^{2+}$ or calmodulin alone (Oh and Yun, 1999).

Petunia GAD is developmentally regulated, and GAD activity can be detected at a very early stage of germination (Chen et al., 1994). Previously, it was shown that plant GADs and NAD kinases (another type of calmodulin-binding protein) are differentially activated by calmodulin isoforms (Lee et al., 1997; Oh and Yun, 1999). The differential abilities of GAD in the binding of calmodulin and calmodulin isoforms suggest that GAD isoforms may have their own target calmodulins. In this regard, it is interesting to note that rice contains several calmodulin isoforms (OsCaMs) (Lee $e t$ al., 2000) and GAD isoforms (OsGADs) (Akama et al., 2001). Future isoform-specific calmodulin-binding assays for OsGAD proteins will help us understand the mechanism by which OsGADs interact with calmodulin.

All plant seeds and cereals contain phytate, which decreases the bioavailability of calcium by chealating $\mathrm{Ca}^{2+}$ (Graf, 1983; Novak and Haslberger, 2000). The levels of plant phytases, phytate hydrolyzing enzymes, are enhanced during the germination of plant seeds (Bartnick and Szafranska, 1987; Laboure et al., 1993). Therefore, increases in soluble calcium ion concentrations in germinated brown rice extracts may be due to the release of $\mathrm{Ca}^{2+}$ from the phytate- $\mathrm{Ca}^{2+}$ complex by the enzymatic hydrolysis of phytate during germination.

Since glutamic acid, which is the precursor of GABA, is one of the most abundant amino acids in brown rice (Oh and Choi, 2000), then understanding the mechanism of synthesis and regulation of GABA may have nutritional and pharmacological significance (Choi et al., 1998; Baek et al., 2000; Lee et al., 2001). Typically, enhanced GABA levels were obtained in germinated rice and barley grain by germinating them with water only (Nakagawa and Onoda 1996, Yun et al. 1998). Our approach for enhancing GABA synthesis in germinating rice may potentially greatly improve GABA yields for research purposes or produce GABA-rich functional foods. Further work with the rice system (including the introduction of genes that are related to GABA synthesis into rice plants and studying the interactions of brown rice components with GABA synthesizing or degrading enzymes from animal sources) may provide further insights into novel nutraceutical applications for germinated brown rice.

Acknowledgments This research was supported by the Research Center for Industrial Development of Biofood Materials at Chonbuk National University, Chonju, Korea. The Center is designated as a Regional Research Center appointed by the Korea Science and Engineering Foundation (KOSEF), Jeollabuk-do Provincial Government and Chonbuk National University. The author thanks In-Tae Lee and KiBum Park for their technical assistance.

\section{References}

Akama, K., Akihiro, T., Kitagawa, M. and Takaiwa, F. (2001) Rice (Oryza sativa) contains a novel isoform of glutamate decarboxylase that lacks an authentic calmodulin-binding domain at the C-terminus. Biochim. Biophys. Acta 1522, 143150.

Arazi, T., Baum, G., Snedden, W. A., Shelp, B. J. and Fromm, H. (1995) Molecular and biochemical analysis of calmodulin: Interactions with the calmodulin-binding domain of plant glutamate decarboxylase. Plant Physiol. 108, 551-561.

Bach, M., Schnitzler, J. P. and Seitz, H. U. (1993) Elicitor-induced changes in $\mathrm{Ca}^{2+}$ influx, $\mathrm{K}^{+}$efflux, and 4-hydroxybenzoic acid synthesis in protoplasts of Daucus carota L. Plant Physiol. 103, 407-412.

Baek, N. I., Ahn, E. M., Han, J. T., Park, J. K., Cho, S. W., Jeon, S. G., Bahn, J. H., Sun, H. J. and Choi, S. Y. (2000) Effects of several medicinal plants on the activity of GABA-metabolizing enzymes. Kor. J. Pharmacogn. 31, 23-27.

Bartnick, M. and Szafranska, J. (1987) Change in phytate content and phytase during the germination of some cereals. J. Cereal Sci. 5, 23-28.

Baum, G., Chen, Y., Arazi, T., Takatsuji, H. and Fromm, H. (1993) A plant glutamate decarboxylase containing a calmodulin binding domain: cloning, sequence, and functional analysis. J. Biol. Chem. 268, 19610-19617.

Baum, G., Lev-Yadun, S., Fridmann, Y., Arazi, T., Katsnelson, H., Zik, M. and Fromm, H. (1996) Calmodulin binding to glutamate decarboxylase is required for regulation of glutamate and GABA metabolism and normal development in plants. EMBO J. 15, 2988-2996.

Bown, A. W. and Shelp, B. J. (1997) The metabolism and functions of $\gamma$-aminobutyric acid. Plant Physiol. 115, 1-5.

Bradford, M. M. (1976) A rapid and sensitive method for the quantitation of microgram quantities of proteins utilizing the principle of protein dye binding. Anal. Biochem. 72, 248-254. 
Chen, Y., Baum, G. and Fromm, H. (1994) The 58-kilodalton calmodulin-binding glutamate decarboxylase is a ubiquitous protein in petunia organs and its expression is developmentally regulated. Plant Physiol. 106, 1381-1387.

Choi, S. Y., Bahn, J. H., Jeon, S. G., Chung, Y. M., Hong, J. W., Ahn, J. Y., Hwang, E. J., Cho, S. W., Park, J. K. and Baek, N. I. (1998) Stimulatory effects of ginsenoside on bovine brain glutamate decarboxylase. J. Biochem. Mol. Biol. 31, 233-239.

Cohen, Y., Niderman, T., Mosinger, E. and Fluhr, R. (1994) $\beta$ Aminobutyric acid induces the accumulation of pathogenesisrelated proteins in tomato Lycopersicum esculentum plants and resistance to late blight infection caused by Phytophthora infestans. Plant Physiol. 104, 59-66.

Collinge, M. and Trewavas, A. J. (1989) The location of calmodulin in the pea plasma membrane. J. Biol. Chem. 262, 8865-8872.

Erlander, M. G. and Tobin, A. J. (1991) The structural and functional heterogeneity of glutamic acid decarboxylase: a review. Neurochem. Res. 16, 215-226.

Graf, E. (1983) Calcium binding to phytic acid. J. Agric. Food Chem. 31, 851-855.

Hepler, P. K. and Wayne, R. O. (1985) Calcium and plant development. Ann. Rev. Plant Physiol. 36, 397-439.

Jung, B. O., Lee, Y. M., Kim, J. J., Choi, Y. J., Jung, K. J., Kim, J. J. and Chung, S. J. (1999) The antimicrobial effect of water soluble chitosan. J. Korean Ind. Eng. Chem. 10, 660-665.

Knight, M. R., Campbell, A. K., Smith, S. M. and Trewavas, A. J. (1991) Transgenic plant aequorin reports the effect of touch and cold-shock and elicitors on cytoplasmic calcium. Nature 352, 524-526.

Laboure, A. M., Gangnon, J. and Lescure, A. M. (1993) Purification and characterization of a phytase (myo-inositolhexakisphosphate phospho-hydrolase) accumulated in maize (Zea mays) seedlings during germination. Biochem. J. 295, 413-419.

Lee, S. H., Seo, H. Y., Kim, J. C., Lee, M. S., Heo, W. D., Chung, W. S., Lee, K. J., Kim, M. C., Cheong, Y. H., Choi, J. Y. and Cho, M. J. (1997) Differential activation of NAD kinase by plant calmodulin isoforms: The critical role of domain I. $J$. Biol. Chem. 272, 9252-9259.

Lee, S. H., Kim, C. Y., Lim, C. O., Lee, S. I., Gal, S. W. and Choi, Y. J. (2000) Molecular characterization of three cDNA clones encoding calmodulin isoforms of rice. Agric. Chem. Biotechnol. 43, 5-11.

Lee, E. Y., Yoon, H. Y., Kim, T. U., Choi, S. Y., Won, M. H. and Cho, S. W. (2001) Inactivation of brain glutamate dehydrogenase isoproteins by MDL 29951. J. Biochem. Mol. Biol. 34, 268-271.

Ling, V., Snedden, W. A., Shelp, B. J. and Assmann, S. M. (1994) Analysis of a soluble calmodulin binding protein from fava bean roots: Identification of glutamate decarboxylase as a calmodulin-activated enzyme. Plant Cell 6, 1135-1143.

Mody, I., Dekoninck, Y., Otis, T. S. and Soltesz, I. (1994) Bringing the cleft at GABA synapses in the brain. Trends Neurosci. 17, 517-525.

Nakagawa, K. and Onota, A. (1996) Accumulation of $\gamma$ aminobutyric acid (GABA) in the rice germ. Shokuhin Kaihatsu 31, 43-46.

Notsu, S., Saito, N., Kosaki, H., Inui, H. and Hirano, S. (1994) Stimulation of phenylalanine ammonia-lysate activity and lignification in rice callus treated with chitin, chitosan, and their derivatives. Biosci. Biotech. Biochem. 58, 552-553.

Novak, W. K. and Haslberger, A. G. (2000) Substantial equivalence of antinutrients and inherent plant toxins in genetically modified novel foods. Food Chem. Toxicol. 38, 473483.

Oh, S. H. and Yun, S. J. (1999) Effects of various calmodulins on the activation of glutamate decarboxylase and nicotinamide adenine dinucleotide kinase isolated from tobacco plants. Agric. Chem. Biotechnol. 42, 19-24.

Oh, S. H. and Choi, W. G. (2000) Production of the quality germinated brown rice containing high $\gamma$-aminobutyric acid by chitosan application. Korean J. Biotechnol. Bioeng. 15, 615620.

Oh, S. H. and Choi, W. G. (2001) Changes in the levels of $\gamma$ aminobutyric acid and glutamate decarboxylase in developing soybean seedlings. J. Plant Res. 114, 309-313.

Oh, S. H. and Cha, Y. S. (2001) Effects of diets supplemented with pharbitis seed powder on serum and hepatic lipid levels and enzyme activities of rats administered with ethanol chronically. J. Biochem. Mol. Biol. 34, 166-171.

Oh, S. H., Kim, S. H., Moon, Y. J. and Choi, W. G. (2002) Changes in the levels of $\gamma$-aminobutyric acid and some amino acids by application of glutamic acid solution for the germination of brown rice. Korean J. Biotechnol. Bioeng. 17, 49-53.

Omori, M., Yano, T., Okamoto, T., Tsushida, T., Murai, T. and Higuchi, M. (1987) Effect of anaerobically treated tea (Gabaron tea) on blood pressure of spontaneously hypertensive rats. Nippon Nogikagaku Kaishi 61, 1449-1451.

Park, J. K., Jin, S. H., Choi, K. H., Ko, J. H., Baek, N. I., Choi, S. Y., Cho, S. W., Choi, K. J. and Nam, K. Y. (1999) Influence of ginsenosides on the kainic acid-induced seizure activity in immature rats. J. Biochem. Mol. Biol. 32, 339-344.

Pearce, R. B. and Ride, J. P. (1982) Chitin and related compounds as elicitors of the lignification response in wounded wheat leaves. Physiol. Plant Pathol. 20, 119-123.

Ramputh, A. and Bown, A. W. (1996) Rapid $\gamma$-aminobutyric acid synthesis and inhibition of the growth and development of oblique-banded leaf-roller larvae. Plant Physiol. 111, 13491353.

Rasi-Caldogno, F., Carnelli, A. and De Michelis, M. I. (1993) Controlled proteolysis activates the plasma membrane $\mathrm{Ca}^{2+}$ pump of higher plants. Plant Physiol. 103, 385-390.

Selman, I. W. and Cooper, P. (1978) Changes in free amino compounds in young tomato plants in light and darkness with particular references to $\gamma$-aminobutyric acid. Ann. Bot. 42, 627636.

Serraj, R., Shelp, B. J. and Sinclair, T. R. (1998) Accumulation of $\gamma$-aminobutyric acid in nodulated soybean in response to drought stress. Physiol. Plantarum 102, 79-86.

Shelp, B. J., Walton, C. S., Snedden, W. A., Tuin, L. G., Oresnik, I. J. and Layzell, D. B. (1995) GABA shunt in developing soybean seeds is associated with hypoxia. Physiol. Plant. 94, 219-228.

Shelp, B. J., Bown, A. W. and McLean, M. D. (1999) Metabolism and functions of gamma-aminobutyric acid. Trends Plant Sci. 4, 446-452.

Snedden, W. A., Arazi, T., Fromm, H. and Shelp, B. J. (1995) Calcium/calmodulin activation of soybean glutamate 
decarboxylase. Plant Physiol. 108, 543-549.

Snedden, W. A. and Fromm, H. (1998) Calmodulin, calmodulinrelated proteins and plant responses to the environment. Trends Plant Sci. 3, 299-304.

Stayanarayan, V. and Nair, P. M. (1990) Metabolism, enzymology and possible roles of 4-aminobutyrate in higher plants. Phytochem. 29, 367-375.
Vandewalle, I. and Olsson, R. (1983) The $\gamma$-aminobutyric acid shunt in germinating Sinapis alba seeds. Plant Sci. Lett. 31, 269-273.

Yun, S. J., Choi, K. G. and Kim, J. K. (1998) Effect of anaerobic treatment on carbohydrate-hydrolytic enzyme activities and free amino acid contents in barley malt. Kor. J. Crop Sci. 43, 19-22. 